\title{
In vitro anti-bacterial activity of Prosopis juliflora leafs extract against pathogenic bacteria
}

\author{
Ali M. Badri ${ }^{1 \star}$, Mohamed I. Garbi ${ }^{1}$, Ahmed S. Kabbashi ${ }^{1}$, Mahmoud S. Saleh ${ }^{1}$, Yousof S. \\ Yousof $^{2}$, Suha F. Mohammed ${ }^{1}$, Ibrahim T. Ibrahim ${ }^{1}$ and Amira A. Magzoub1 \\ ${ }^{1}$ Department of Microbiology, Faculty of Medical Laboratory Sciences, International University of Africa. P.O. Box 2469 \\ Khartoum, Sudan. \\ ${ }^{2}$ Department of Microbiology, Faculty of Medical Laboratory Sciences, Elrazi University, Khartoum, Sudan.
}

Accepted 29 November, 2016

\begin{abstract}
Prosopis juliflora is the most widespread species of genus Prosopis and it is a good source of compounds that have been shown to be pharmacologically active. This plant has been used as a traditional treatment for several diseases such as microbial infections are major public health problems in the developed and developing countries. Infectious disease is a major cause of deaths accounting for one-half of all deaths in tropical countries. Therefore, this study was carried out to investigate the in vitro antimicrobial activity of Prosopis juliflora methanolic leafs extract against clinical isolates performed by cup-plate agar diffusion method against seven Gram negative bacteria: Escherichia coli, Escherichia coli ESBL, Shigella flexneri, Salmonella typhi, Proteus mirabilis, Pseudomonas aeruginosa, and Klebsiella pneumoniae; and three Gram positive bacteria: Enterococcus faecalis, Listeria monocytogenes and Bacillus cereus. The methanolic extract exhibited inhibitory effects against most of the tested microorganisms with zone of inhibition ranging from 12 to $41 \mathrm{~mm}$. The largest inhibition zone were obtained from methanolic extract of $P$. juliflora (leaf) against the Gram negative $P$. aeruginosa $(41 \mathrm{~mm})$ in $100 \mathrm{mg} / \mathrm{ml}$ concentration, and Gram positive $L$. monocytogenes $(33 \mathrm{~mm}$ ) in $100 \mathrm{mg} / \mathrm{ml}$ concentration in comparison with Gentamicin $10 \mathrm{mgc}$. The methanol extract of Prosopis juliflora was found effective against different species of bacteria and considered for further exploration and isolation active compounds analysis.
\end{abstract}

Keywords: In vitro, antibacterial, Prosopis juliflora, pathogenic, Sudan.

${ }^{*}$ Corresponding author. E-mail: ali.almhasi@gmail.com.

\section{INTRODUCTION}

Microbial infections are major public health problems in the developed and developing countries. Antibiotics are used to treat these infections. Due to indiscriminate use of commercial antibiotics, the incidence of multiple antibiotic resistance in human pathogens is increasing (Jeyachandran and Mahesh, 2007). Infectious diseases caused by bacteria and fungi affect millions of people worldwide, throughout the history of mankind, infectious diseases have remained a major cause of death and disability. Today infectious diseases account for one-third of all deaths in the world; the World Health Organization estimates that nearly 50,000 people die each day throughout the world from infectious diseases. The discovery of antibiotics was an essential part in combating bacterial infections that once ravaged humankind (Usha et al., 2010). The development and spread of resistance to currently available antibiotics is a worldwide concern, the increasing phenomenon of acquisition of resistance among microorganisms to antimicrobial drugs is attributed to the indiscriminate and improper use of current antimicrobial drugs (Usha et al., 2010).

The use of plants and herb extract in the treatment of human ailments is a very ancient art, a practice that has been passed on for generations and scientists in Africa and other developing countries and other are conducting research into local plants abundant in the continent for their possible use in traditional medicine (Nneamaka, 1991). Similar to other developing countries, traditional medical practices play an important role in Sudan. Herbal 
drugs are of major importance in Sudanese folk medicine. This was documented during comprehensive ethnobotanical investigations of El Kamali and Khalid (1996), El Ghazali et al. (1994), El Ghazali et al. (1997) and El Kamali and El Khalifa (1999). These authors listed the most common herbal remedies of Sudan, based mainly on interviews with traditional healers. Among these plants are many used for the treatment of diarrhea and stomach pain. A number of systematic attempts have been made to verify the claimed antibacterial uses of Sudanese plants and to detect and/or isolate their bioactive agents (Khalid et al., 1986, Khalid et al., 1989, Khalid et al., 1998, El Kamali and El Khalifa, 1997, El Tahir et al., 1998, El Tahir et al., 1999). P. juliflora is used to treat colds, diarrhea, dysentery, inflammation, itch, measles, sore throat, wounds and sexually transmitted diseases. The plant also possessed antiemetic, antibacterial, expectorant and antiseptic activities. Its juice is used in folk remedies for the cancerous condition, pain and inflammation are common complaints in many patients suffering from acute conditions (Vikrant and Arya, 2001; Vogel, 2002). Anti-inflammatory agents inhibit the synthesis of prostaglandin synthesis which is one of the most important mediators of inflammation. Other mechanism of anti inflammatory activity the stabilization of lysosomal membrane in leucocytes (lysosomal enzymes destroy cartilage and other issues and perpetuate inflammation) and antagonism of certain actions of bradykinin (Tripathi, 1994).

\section{MATERIALS AND METHODS}

\section{Plant materials}

The Prosopis juliflora (leaf) were collected from central Sudan between January 2015 and February 2015. The plant was identified and authenticated by the taxonomists of Medicinal and Aromatic Plants and Traditional Medicine Research Institute (MAPTMRI). The leafs were air-dried, under the shadow with good ventilation and then ground finely in a mill until their uses for extracts preparation.

\section{Preparation of crude extracts}

Extraction was carried out for the leaf of Prosopis juliflora L. (leaf) plant by using overnight maceration techniques according to the method described by Harborne (1984). About $50 \mathrm{~g}$ were macerated in $250 \mathrm{ml}$ of methanol for $3 \mathrm{~h}$ at room temperature with occasional shaking for $24 \mathrm{~h}$ at room temperature, the supernatant was decanted and clarity field by filtration through a filter paper, after filtration, the solvent was then removed under reduced pressure by rotary evaporator at $55^{\circ} \mathrm{C}$. Each residue was weighed and the yield percentage was calculated then stored at $4^{\circ} \mathrm{C}$ in tightly sealed glass vial ready for use.

\section{Standard antibiotic}

Gentamicin (10 $\mu \mathrm{g} / \mathrm{disc})$ antibiotic discs used in the present study were procured by $\mathrm{Hi}$ media Chemicals Ltd, Mumbai, India and stored at $4^{\circ} \mathrm{C}$.

\section{Collection of bacteria strains}

The methnolic extract solution of Prosopis juliflora was tested against bacterial species. Various clinical isolates were obtained from The Royal Care International Hospital located at Burri, Khartoum State, Sudan. All Isolates bacteria were identified and characterized using standard microbiology technique (Chessbrough, 2006). The bacterial cultures were maintained on nutrient agar and inoculated at $37^{\circ} \mathrm{C}$ for $24 \mathrm{~h}$ and then used for tests.

\section{In vitro testing of extracts for antibacterial activity}

\section{Testing for antibacterial activity}

The cup-plate agar diffusion method (Kavanagh, 1972), was adopted with some minor modifications to assess the antibacterial activity of the prepared extracts. One $\mathrm{ml}$ of the isolated bacterial stock suspension $\left(10^{8}\right.$ to $\left.10^{9} \mathrm{CFU} / \mathrm{ml}\right)$ were thoroughly mixed with $100 \mathrm{ml}$ of molten sterile Mueller Hinton Agar which was maintained at $40^{\circ} \mathrm{C} .20 \mathrm{ml}$ aliquots of the inoculated Mueller Hinton Agar were distributed into sterile Petri-dishes. The agar was left to set and all of these plates 4 cups (10 $\mathrm{mm}$ in diameter) were cut using a sterile cork borer (No. 4) and agar discs were removed. The cups were filled with $0.1 \mathrm{ml}$ sample of each extracts using automatic microlitre pipette, and allowed to diffuse a room temperature for two hours. The plates were then incubated in the upright position at $37^{\circ} \mathrm{C}$ for $24 \mathrm{~h}$. The plates were observed for the presence of inhibition of bacterial growth that was indicated by a clear zone around the wells. The size of the zones of inhibition was measured and the antibacterial activity was expressed in terms of average diameter of the zone of inhibition in millimeters. The results were compared with the standard antibiotics Gentamicin $(10 \mu \mathrm{g} / \mathrm{disc})$.

\section{Statistical analysis}

Antimicrobial activity experiments were repeated thrice in triplicates each time and the means \pm standard deviation (SD). Statistical analysis for all the assays results were done using Microsoft Excel program (2010).

\section{RESULTS AND DISCUSSION}

The yield is $22.1 \%$ of Prosopis juliflora methanol extract. The leaf of Prosopis juliflora family (Fabaceae) were screened for antibacterial activity against seven Gram negative bacteria (Escherichia coli, Escherichia coli ESBL, Shigella flexneri, Salmonella typhi, Klebsiella pneumoniae, Pseudomonas aeruginosa and Proteus mirabiliss), and three Gram positive bacteria (Enterococcus faecalis, Listeria monocytogenes and Bacillus cereus) using the cup-plate agar diffusion method. The extract obtained from the leaf of $P$. juliflora exerted pronounced activity against several bacteria strains tested as indicated by diameter of growth inhibition zones that varied from (12 to $41 \mathrm{~mm}$ ) except $S$. typhi has no inhibition zones (Table 1).

Out of the ten cultures tested, it showed good activity 
Table 1. Antibacterial activity of $P$. juliflora (leaf) against the clinical isolates bacterial.

\begin{tabular}{lc}
\hline Standard microorganisms & Mean diameter of growth inhibition zone $(\mathbf{m m})$ \\
\hline Escherichia coli & $21 \pm 0.21$ \\
Escherichia coli ESBL & $31 \pm 0.13$ \\
Shigella flexneri & $28 \pm 0.19$ \\
Salmonella typhi & - \\
Proteus mirabiliss & $12 \pm 0.20$ \\
Pseudomonas aeruginosa & $41 \pm 0.22$ \\
Klebsiella pneumoniae & $22 \pm 0.15$ \\
Bacillus cereus & $31 \pm 0.30$ \\
Enterococcus faecalis & $21 \pm 0.21$ \\
Listeria monocytogenes & $33 \pm 0.20$ \\
\hline
\end{tabular}

Key: Interpretation of results: MDIZ $(\mathrm{mm}):>18 \mathrm{~mm}$ : Sensitive, 14 to $18 \mathrm{~mm}$ : Intermediate: <14 mm: Resistant. (-): No inhibition; Concentration used $100 \mathrm{mg} / \mathrm{ml}$ at $0.1 \mathrm{ml} / \mathrm{cup}$.

Table 2. The antibacterial activity of $P$. juliflora and reference antibiotic against the isolated bacteria.

\begin{tabular}{clccccc}
\hline & & \multicolumn{5}{c}{ Concentrations (mg/ml) } \\
\cline { 3 - 6 } No. & Tested bacteria & $\mathbf{1 0 0}$ & $\mathbf{5 0}$ & $\mathbf{2 5}$ & $\mathbf{1 2 . 5}$ & Gentamicin 10 $\mathbf{~ g c}$ \\
\cline { 3 - 6 } & & $21 \pm 0.21$ & $19 \pm 0.17$ & $17 \pm 0.13$ & $15 \pm 0.14$ & 30 \\
\hline 1 & Escherichia coli & $31 \pm 0.13$ & $26 \pm 0.2$ & $25 \pm 0.16$ & $24 \pm 0.21$ & 25 \\
2 & Escherichia coli ESBL & $28 \pm 0.19$ & $25 \pm 0.11$ & $22 \pm 0.13$ & $20 \pm 0.09$ & 25 \\
3 & Shigella flexneri & - & - & - & - & 25 \\
4 & Salmonella typhi & $12 \pm 0.20$ & - & - & - & 24 \\
5 & Proteus mirabiliss & $41 \pm 0.22$ & $37 \pm 0.12$ & $30 \pm 0.17$ & $29 \pm 0.12$ & 32 \\
6 & Pseudomonas aeruginosa & $22 \pm 0.15$ & $21 \pm 0.21$ & $10 \pm 0.31$ & $16 \pm 0.21$ & 21 \\
7 & Klebsiella pneumoniae & $31 \pm 0.30$ & $30 \pm 0.2$ & $25 \pm 0.14$ & $22 \pm 0.2$ & 27 \\
8 & Bacillus cereus & $21 \pm 0.21$ & $20 \pm 0.23$ & $19 \pm 0.27$ & $17 \pm 0.22$ & 20 \\
9 & Enterococcus faecalis & $33 \pm 0.20$ & $28 \pm 0.4$ & $23 \pm 0.21$ & - & 28 \\
10 & Listeria monocytogenes & & & & & \\
\hline
\end{tabular}

against $P$. aeruginosa $(41 \mathrm{~mm})$ and $L$. monocytogenes $(33 \mathrm{~mm})$, B. cereus and E. coli ESBL $(31 \mathrm{~mm})$, S. flexneri $(28 \mathrm{~mm}), K$. pneumonia $(22 \mathrm{~mm}), E$. coli and $E$. faecalis $(21 \mathrm{~mm})$ and $P$. mirabilis $(12 \mathrm{~mm})$ at the highest concentration checked $(100 \mathrm{mg} / \mathrm{ml})$. Methanol extract of leafs was also able to show fairly good activity against Gram positive and negative species. On comparison, only P. mirabiliss show $12 \mathrm{~mm}$ inhibition zone in concentration $(100 \mathrm{mg} / \mathrm{ml})$. For each test control positive Gentamicin in concentration $10 \mathrm{mgc}$ with zone of inhibition ranging from (20 to $32 \mathrm{~mm}$ ) against all bacteria strains tested.

The result of minimum inhibition concentration from Table 2 showed that $12.5 \mu \mathrm{gg} / \mathrm{ml}$ was the lowest concentration at which all the tested microorganisms were inhibited A comparison of observation given in Tables 2 showed that the Flowers of $P$. juliflora dissolved in methanol inhibited $E$. coli $\mathrm{ESBL}, S$. flexneri, $P$. aeruginosa, K. pneumonia, B. cereus, $E$. faecalis and $L$. monocytogenes higher than $10 \mu \mathrm{g} / \mathrm{ml}$ Gentamicin.

Antibiotics provide the main basis for the therapy of bacterial infections. However, the high genetic variability of bacteria enables them to rapidly evade the action of antibiotics by developing antibiotic resistance. Thus, there has been a continuing search for new and more potent antibiotics (Heisig, 2001). In our study the antibacterial activity of methanol extract of $P$. juliflora were evaluated and the result indicates that $P$. juliflora has activity against of the strains tested. This study are compatible with many of the studies that say: $P$. juliflora is commonly used to treat eye conditions, open wounds and dermatological ailments. Acting much as an antacid it can also treat digestive problems (Davidow, 1999). $P$. juliflora has antibiotic activity and its aqueous extracts are antibacterial (Kay, 1996). It has soothing, astringent, and antiseptic properties (Davidow, 1999). The in vitro in activity of this medicinal plant against pathogenic bacterial strains as established in this study does not therefore necessarily translate to their in vivo activity but may probably be playing an immuno-modulatory role in the body system. This effect has been documented were immuno-modulation (in vivo) of chemical compounds 
from medicinal plants, many of which have been proven to be inactive in-vitro against pathogen (Oliver-Bever, 1986). Among the tested, methanol extract exhibited the highest antimicrobial activity; this may be due to stronger extraction capacity of active component responsible for antibacterial activity. And the differences in the type and concentrations of the secondary metabolites across different plants, variation in antimicrobial activities are expected. These quantitative and qualitative differences in constituents are influenced by the chemo types and particularly by environmental factors and method of extraction. Also the antimicrobial activity of methanol extract is also high compared. Although, we did not determined the actual composition of our methanol plant extract since several studies demonstrated that crude plants extracts bio-activity was superior to that of their purified fractions due to the additive or synergistic activity (Kamatu et al., 2006).

\section{CONCLUSION}

The leaf extracts of $P$. juliflora showed the various degree of inhibitory activity against different species of bacteria. Results obtained justified the use of the Sudanese leaf of $P$. juliflora as antimicrobial therapy in traditional medicine in Sudan and the neighboring countries. Further investigations regarding the mode of action and other related pharmacological studies such as in vivo investigation, drug formulation and clinical trials are highly recommended.

\section{ACKNOWLEDGEMENTS}

The authors are grateful to Dr. Sara Mohamed Ali, Head Department of Microbiology, Faculty of Medical Laboratory Sciences, International University of Africa.

\section{REFERENCES}

Chessbrough $\mathrm{M}$, 2006. District laboratory practice in tropical countries Part two, 2nd Edn. Cambridge University Press, UK., 123-201.

Davidow J, 1999. Infusions of Healing: A treasury of Mexican-American herbal remedies. Simon and Schuster Inc. pp 149.

El Ghazali GB, El Tohami MS, El Egami AB, 1994. Medicinal Plants of the Sudan. Part III. Medicinal Plants of the White Nile Province. Khartoum University Press, Sudan.

El Ghazali GB, El Tohami MS, El Egami AB, Abdalla WS, Mohammed MG, 1997. Medicinal Plants of the Sudan. Part IV. Medicinal Plants of Northern Kordofan. Omdurman Islamic University Press, Khartoum, Sudan.

El Kamali HM, El Khalifa KF, 1997. Treatment of malaria through herbal drugs in the Central Sudan. Fitoterapia, 68(6): 527-528.

EI Kamali HM, EI Khalifa KF, 1999. Folk medicinal plants of riverside forests of the southern Blue Nile district, Sudan. Fitoterapia, 70: 493497.

El Kamali HM, Khalid SA, 1996. The most common herbal remedies in Central Sudan. Fitoterapia, 57: 301-306.
El Tahir A, Ibrahim A, Satti GMH, Theander TG, Kharazmi A, Khalid SA, 1998. The potential antileishmanial activity of some Sudanese medicinal plants. Phytother Res, 12:576- 579.

El Tahir A, Satti GM, Khalid SA, 1999. Antiplasmodial activity of selected Sudanese plants with emphasis on Acacia nilotica. Phytother Res, 13: 474-478.

Harborne JB, 1984. Phytochemical methods. Second edition. Chapman and Hall.

Heisig P, 2001. Inhibitors of bacterial topoisomerases: Mechanisms of action and resistance and clinical aspects. Planta Medica, 67: 3-12.

Jeyachandran R, Mahesh A, 2007. Enumatration of antidiabetic herbal flora of Tamilnadu. Res J Med Plant, 1:144-148.

Kamatu GP, Viljoen A, Van Vuuren SF, Van Zye RL, 2006. In-vitro evidence of antimicrobial synergy between Savia chamelaeagea and Leontis leonurus. S Afr J Bot, 72: 634-636.

Kavanagh F, 1972. Analytical Microbiology. Vol II. Academic press (Pub), New York and London, pp 11.

Kay MA, 1996. Healing with plants in the American and Mexican West. Tuscon: The University of Arizona Press, 221-224.

Khalid SA, Duddeck H, Gonzalez-Sierra M, 1989. Isolation and characterization of an antimalarial agent of the neem tree Azadirachta indica. J Nat Prod, 52(2): 922-926.

Khalid SA, Friedrichsen GM, Kharazmi A, Theander TG, Olsen CE, Christensen SB, 1998. Limonoids from Khaya senegalensis. Phytochemistry, 49(6): 1769-1772.

Khalid SA, Mustafa AF, George TG, Jensen JB, 1986. Potential antimalarial candidates from African plants an in vitro approach using Plasmodium falciparum. J Ethnopharmacol, 15: 201-209.

Nneamaka Al, 1991. Screening of some Nigerian medicinal plants for bacterial activity. M.Sc. Thesis A. B. U. Zaria.

Oliver-Bever B, 1986. Medicinal Plants in Tropical West Africa. London: Cambridge University Press. pp. 117-118.

Tripathi KD, 1994. Essentials of Medical Pharmacology. 3rd ed. New Delhi; Jaypee brothers medical Publishers (P) Ltd. pp. 406.

Usha PTA, Jose S, Nisha AR, 2010. Antimicrobial drug resistance - a global concern. Vet World, 3:138-139.

Vikrant A, Arya ML, 2001. A Review on anti-inflammatory plant barks. Int J Pharm Tech, 3(2): 899-908.

Vogel HG, 2002. Drug discovery and evolution. 2nd ed, Springer publication, New York; pp. 772-773.
Citation: Badri AM, Garbi MI, Ahmed S. Kabbashi AS, Saleh MS, Yousof YS, Mohammed SF, Ibrahim IT, Magzoub AA, 2017. In vitro anti-bacterial activity of Prosopis juliflora leafs extract against pathogenic bacteria. Adv Med Plant Res, 5(1): 1-4. 